\title{
VEGETATION INFLUENCED HYDRODYNAMICS AND SEDIMENT TRANSPORT
}

\author{
Sha LOU, Tongji University, lousha@tongji.edu.cn \\ Ming CHEN*, Tongji University, chenming201291@163.com \\ Shuguang LIU, Tongji University, liusgliu@tongji.edu.cn \\ Guihui ZHONG, Tongji University, guihui_zhong@tongji.edu.cn
}

Tidal flat is a transition zone between land and ocean. Vegetation in tidal flat can protect the coastal areas from storm surge and tsunamis by wave energy reduction. Tidal flat also can filter parts of the artificial contaminations and reduce the pollutants discharged into the ocean. In addition, interactions between vegetation and morphology over tidal flat have strong impacts on ecological regime and morphological evolution. However, there are too many complex physical processes involving in the interaction among hydrodynamics, sediment transport and vegetation. Therefore, a flume study was carried out in this paper to study the effects of vegetation on hydrodynamics and sediment transport.

\section{EXPERIMENTAL DESIGN}

All the experiments were conducted in a wave flume constructed in the Hydraulic Laboratory at Tongji University, China. The wave flume is $50 \mathrm{~m}$ long and $0.8 \mathrm{~m}$ wide. A wave generator is placed at the left side of the flume. The right end is equipped with wave absorption system. The mimic vegetation was constructed by putting stiff wooden cylinders in holes drilled in the false bottom. Three different types of vegetation configurations were tested in the experiments (Table 1). In all the configurations, the vegetation zone is $6.0 \mathrm{~m}$ long and $0.8 \mathrm{~m}$ wide (Figure 1). The center of the vegetation zone was located at $15.0 \mathrm{~m}$ from the wave maker. The diameter of cylinders is 8 $\mathrm{mm}$. Plenty model sand with uniform diameter $0.16 \mathrm{~mm}$ and density of $0.7 \mathrm{~g} / \mathrm{cm}^{3}$ is set at the bottom of vegetation zone. Experiments of three kinds of vegetation configuration with different density were carried out under regular wave, unidirectional flow and the combination of wave and flow, respectively (Table 2). Four capacitance-type wave gauges (G1G4) were installed along the flume to measure wave heights. Acoustic Doppler Velocimetry (ADV) was used to measure three dimensional velocities. The data recorded by ADV were adopted only when the signal-to-noise ratio (SNR) was greater than $15 \mathrm{~dB}$, and the correlation (COR) was greater than 70 . Turbidity were directly measured by the turbidity sensor (Campbell Scientific OBS).

Table 1 Vegetation conditions

\begin{tabular}{|c|c|c|c|c|}
\hline & $\begin{array}{c}\text { Diameter } \\
(\mathrm{m})\end{array}$ & $\begin{array}{c}\text { Vegetation } \\
\text { height }(\mathrm{m})\end{array}$ & $\begin{array}{c}\text { Stem } \\
\text { number }\end{array}$ & $\begin{array}{c}\text { Density } \\
\left(\mathrm{stems} / \mathrm{m}^{2}\right)\end{array}$ \\
\hline Case-a & 0.008 & 0.4 & 806 & 167 \\
\hline Case-b & 0.008 & 0.4 & 1599 & 333 \\
\hline \multirow{3}{*}{ Case-c } & \multirow{2}{*}{0.008} & 0.2 & 431 & \multirow{2}{*}{166.5} \\
\cline { 3 - 4 } & & 0.4 & 369 & \multirow{2}{*}{} \\
\cline { 3 - 4 } & & 0.6 & 369 & \\
\cline { 3 - 4 } & & 0.8 & 430 & \\
\hline
\end{tabular}

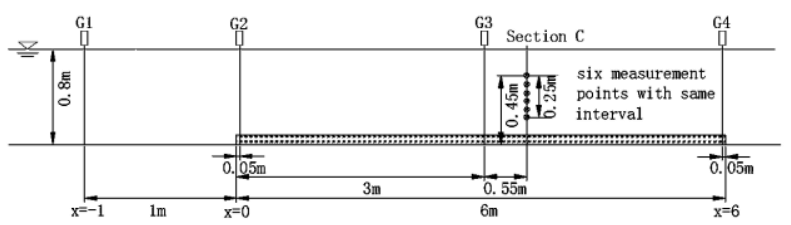

Figure 1 Locations of wave gauges (G1-G4), and ADV/OBS (Section C)
Table 2 Experimental wave and flow conditions

\begin{tabular}{|c|c|c|c|c|}
\hline test 1 & Unidirectional & \multirow{4}{*}{$\begin{array}{l}\text { Water } \\
\text { depth } \\
0.8 \mathrm{~m}\end{array}$} & \multicolumn{2}{|c|}{ Discharge $140 \mathrm{~L} / \mathrm{s}$} \\
\hline test 2 & Wave & & $\begin{array}{c}\text { Wave height } \\
0.06 \mathrm{~m}\end{array}$ & $\begin{array}{c}\text { Wave } \\
\text { period } 1.8 \mathrm{~s}\end{array}$ \\
\hline test 3 & Wave & & $\begin{array}{c}\text { Wave height } \\
0.08 \mathrm{~m}\end{array}$ & $\begin{array}{c}\text { Wave } \\
\text { period } 1.8 \mathrm{~s}\end{array}$ \\
\hline test 4 & Wave & & $\begin{array}{c}\text { Wave height } \\
0.10 \mathrm{~m}\end{array}$ & $\begin{array}{c}\text { Wave } \\
\text { period } 1.8 \mathrm{~s}\end{array}$ \\
\hline test 5 & \multicolumn{4}{|c|}{$\frac{1}{\text { Combination of test } 1 \text { and test } 2}$} \\
\hline test 6 & \multicolumn{4}{|c|}{ Combination of test 1 and test 3} \\
\hline test 7 & \multicolumn{4}{|c|}{ Combination of test 1 and test 4} \\
\hline
\end{tabular}

\section{RESULTS AND DISCUSSIONS}

\section{(1) Mean velocity $u$}

Instantaneous velocities were recorded by $\mathrm{ADV}$ at six locations with same interval in Section C. Mean velocity $u$ were calculated as shown in Figure 2(a,b,c).

The vertical distributions of mean velocity in test 1 , test 4 and test7 are similar under the effect of vegetation with uniform density in Case-a and Case-b. In test1, the mean velocity in Case-a is similar to that in Case-b above $z=0.4 \mathrm{~m}$ where are without vegetation. Below $z=0.4 \mathrm{~m}$, the mean velocity in Case$a$ is larger than that in Case-b due to the relatively higher vegetation density. In Test 4 , the mean wave velocity in Casea is similar to that in Case-b, because the wave motion is above the wave trough in the upper water layer where have less influence of vegetation. In test7, the mean velocity patterns are similar to that in test 1 in both Case-a and Case-b due to the large velocity of unidirectional flow. It's obvious that high vegetation density in Case-b have more impact on velocity distribution, especially near water bottom.

Affected by vegetation with vertically varying density (Casec), the vertical distributions of mean velocity in test 1 , test 4 and test7 are quite different with those under the influence of vegetation with uniform density (Case-a and Case-b). In case$\mathrm{c}$, the vegetation heights range from $0.2 \mathrm{~m}$ to $0.8 \mathrm{~m}$ through the whole water column and it causes relatively small velocity gradients than those in Case-a and Case-b. There apparently has a inflexion point of mean velocity around $z=0.35 \mathrm{~m}$ in test 7 . Above that point, the mean velocity are almost uniform.

\section{(2) Turbulent kinetic energy (TKE)}

Turbulent kinetic energy (TKE) were analyzed using the measured instantaneous velocities at six locations in Section $\mathrm{C}$ as shown in Figure 2(d,e,f).

As the same as mean velocity, the vertical distributions of $T K E$ in test 1 , test 4 and test 7 are similar under the effect of vegetation with uniform density in Case-a and Case-b, while big difference occurs in Case-c. In test 1 , the TKE is decreasing from the upper layer to water bottom in both Case-a and Caseb. Case-b has lower TKE overall water column due to higher vegetation density, except around $z=0.4 \mathrm{~m}$. In test 4 , the magnitude of TKE is much lower under wave motion than that under flow condition. The TKE is higher in Case-b between $z=0.25 \mathrm{~m}-0.35 \mathrm{~m}$. Comparing with results in test 1 , the distribution of TKE has no significant change under the 

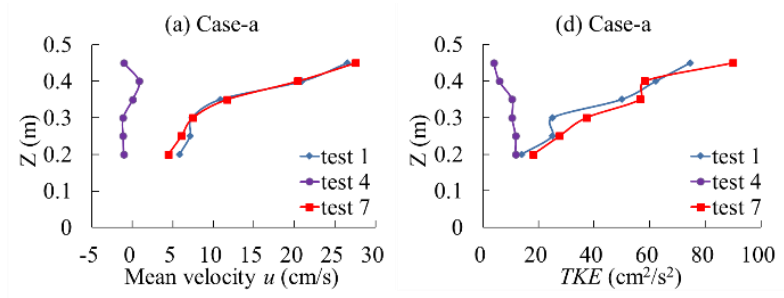

(b) Case-b
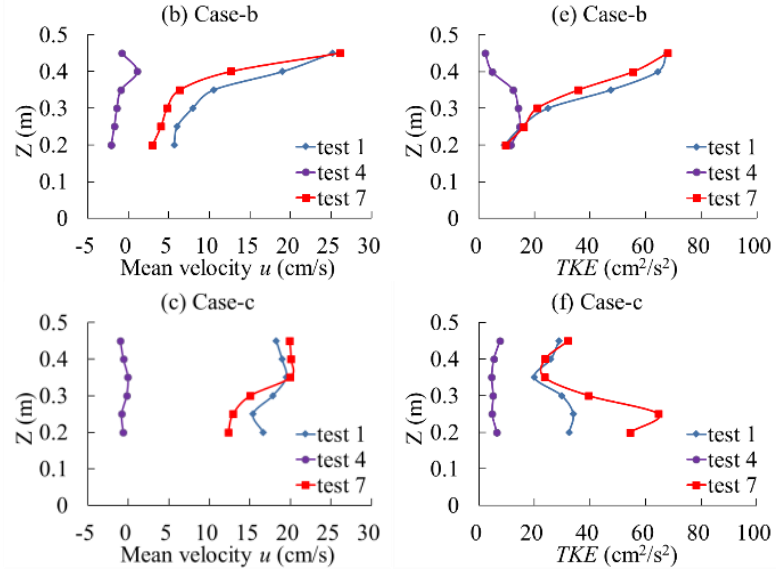

Figure 2 Mean velocity $u$ and turbulent kinetic energy (TKE)

combination of wave and flow (test7) in Case-b, while it's obviously increased in case-a with lower vegetation density. It's indicated that the turbulence under flow condition in our experiment is caused by the canopy-scale turbulence which is suppressed by the high vegetation density, while it's dominated by stem-scale turbulence in wave condition in our experiment which is higher around the vegetation top. Under the combination of wave and flow, it depends on the rate of wave and flow. In our case, the motion of flow is much stronger than that of wave, which results in the prevailing canopy-scale turbulence.

Under the effect of vegetation with vertically varying density (Case-c), the vertical distributions of $T K E$ has been greatly changed. In test 1 , the $T K E$ is severely increased near water bottom (below $z=0.25 \mathrm{~m}$ ) and decreased in the upper layer. In Case-c, the largest vegetation height is $0.8 \mathrm{~m}$, the same as water depth, which suppresses the canopy-scale turbulence, and the linear distribution of vegetation density with higher density near the bottom causes higher stem-scale turbulence. In test 4 , the $T K E$ becomes larger in the upper layer and smaller near bottom, because of the wave motion wave motion above the wave trough in the upper water layer. In test7, the $T K E$ is similar to that in test 1 with higher value near bottom. vegetation with vertically varying density could induced much strong turbulence near bottom under the combination of wave and flow condition.

\section{(3) Sediment distributions}

Sediment distributions were analyzed using the measured data by OBS at six locations in Section $\mathrm{C}$ as shown in Figure 3.

In flow condition (test1), sediment concentration is higher near water bottom in all three vegetation configurations. The concentration in Case-b is higher than that in Case-a below $z=0.4 \mathrm{~m}$. According to the $T K E$ results, the $T K E$ is slightly higher in Case-b around $z=0.4 \mathrm{~m}$. It's similar results as in (Tinoco and coco, 2016). Although the velocity is significantly damped affected by dense vegetation, the sediment suspension increases because of the vegetationinduced turbulence. The concentration in Case-c is similar to that in Case-b around $z=0.2 \mathrm{~m}$ due to the same stem number,

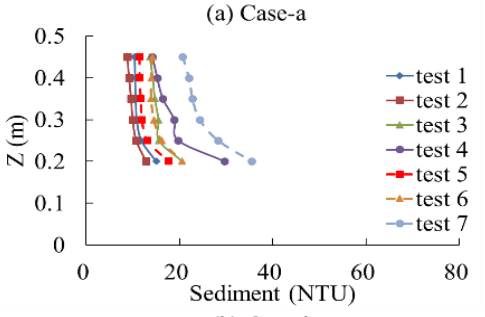

(b) Case-b

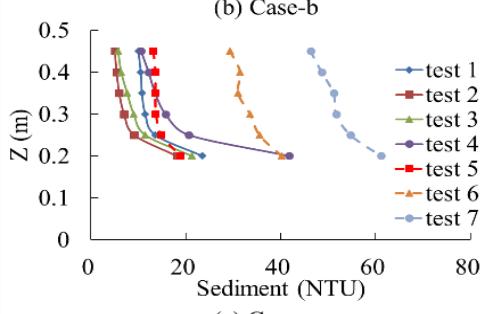

(c) Case-c

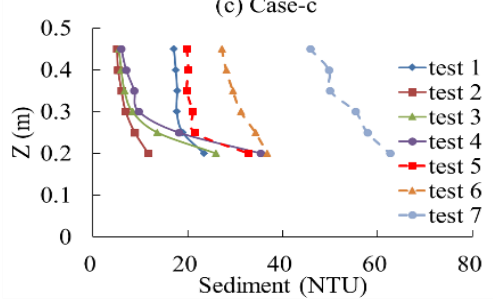

Figure 3 Sediment distributions

while concentrations in other layers are much higher in Case$\mathrm{c}$ than those in Case-a and Case-b. In unidirectional flow, the vegetation with vertically varying density could encouraged sediment suspension.

In wave conditions (test2-test4), high density in Case-b only causes greater concentration around $z=0.2 \mathrm{~m}$ (higher $T K E$ in Case-b between $z=0.25 \mathrm{~m}-0.35 \mathrm{~m}$ ), while concentration in Case-a is larger in other layers. The vegetation with vertically varying density has less influence on sediment distribution under wave condition than that under unidirectional flow. Although the TKE becomes larger in the upper layer in casec, the concentration is the lowest in Case-c in upper layer. Near water bottom, the concentration in Case-c is between those in Case-a and Case-b. But because the concentration is too small $(<10 \mathrm{NTU})$ under wave condition, we can't get more conclusions from it.

Under the combinations of wave and flow (test5-test7), influence of vegetation on sediment concentration is similar to that under flow condition as the vertically varying vegetation density causes the most severely sediment suspension (Case-c> Case-b> Case-a). as the increasing of wave height, the difference of sediment concentration between Case-c and Case-b gets smaller, while that between Case-b and Case-a gets larger.

\section{ACKNOWLEDGEMENT}

This work was sponsored by the Natural Science Foundation of China (Grant No. 41602244). The authors also acknowledge the financial support of the Fundamental Research Funds for the Central Universities of China (22120180095).

\section{REFERENCES}

Dalrymple, R.A., Kirby J.T., and Hwang P.A.. (1984): Wave diffraction due to areas of energy dissipation. Journal of Waterway, Port, Coastal, and Ocean Engineering, Vol 110(1), pp.67-79.

Tinoco, R.O., and Coco, G.. (2016): A laboratory study on sediment resuspension within arrays of rigid cylinders. Advances in Water Resources, Vol 92, pp.1-9. 